\title{
The Experimental Investigation of Hydraulic Fracture Propagation Characteristics in Glutenite Formation
}

\author{
Zhihong Zhao, ${ }^{1}$ Jianchun Guo, ${ }^{1}$ and Shou $\mathrm{Ma}^{1,2}$ \\ ${ }^{1}$ State Key Laboratory of Oil and Gas Reservoir Geology and Exploitation, Southwest Petroleum University, Chengdu 610500, China \\ ${ }^{2}$ Production Technology Research Institute, Shengli Oilfield, SINOPEC, Dongying 257000, China \\ Correspondence should be addressed to Zhihong Zhao; swpuzzh@163.com
}

Received 13 June 2014; Revised 12 November 2014; Accepted 15 November 2014

Academic Editor: Guocheng Lv

Copyright (c) 2015 Zhihong Zhao et al. This is an open access article distributed under the Creative Commons Attribution License, which permits unrestricted use, distribution, and reproduction in any medium, provided the original work is properly cited.

\begin{abstract}
Hydraulic fracture propagation characteristics in glutenite formation are studied by a series of servo-controlled triaxial large-scale fracturing experiments. The experimental results show that the fractures extend along the gravel and sandstone cementing face, and fracture geometry in glutenite formation is complex, which is similar to network fractures. The phenomenon of the gravel being split has not been observed. In the process of the fracture extension, the extension pressure is fluctuating, and the degree of fluctuation is more drastic with the gravel diameter increase. This paper suggests that using large rate and multislug technology would increase the flow ability of the carrying fluid. The conclusions are significant to hydraulic fracturing in glutenite formation.
\end{abstract}

\section{Introduction}

Glutenite reservoir is widely distributed in China, such as the Sheng Li oil field and Xinjiang oil field. Hydraulic fracturing is the key technology used in the exploitation of this kind of reservoir. But the hydraulic fracture extension pressure is influenced by the gravel in glutenite reservoir, which usually leads to the failure of the fracturing treatment. When the hydraulic fracture meets gravels in the process of propagation, as the lithology mutations, the hydraulic fracture propagation direction and geometry would be altered.

Many scholars use large-scale triaxis hydraulic fracturing simulation experiment device to simulate the hydraulic fracture extension and geometry under various reservoir conditions. Chen et al. [1, 2] and Jin et al. [3] performed a series of large-scale triaxial experiments to investigate the influence of natural fractures and earth stress on the induced fractures. They took into account the influence of the natural fracture strike and dip. Bohloli and de Pater [4] performed a series of large-scale triaxial experiments to study the hydraulic fracturing in soft rocks. They observed that fractures obtained at high stress were short, branched, and tortuous while those obtained at low stress were mainly longer, straight, and less tortuous. Chen et al. [5] studied the dynamic fracture propagation in hydraulic refracturing. Yan et al. [6] conducted scaled laboratory experiments to investigate hydraulic fracture initiation mechanisms in porous reservoirs and fractured reservoirs. They observed that the fracture propagation pressure is smooth and steady. Liu et al. [7] simulated the influence of natural fracture network on the propagation geometry of hydraulic fractures.

This paper conducted a series of hydraulic fracture initiation tests with a large-scale triaxis hydraulic fracturing simulation experiment device and artificial glutenite core with different gravel diameters. Through the observation and analysis of fracture profile and pressure curve, the characteristics of hydraulic fracture geometry and propagation in glutenite reservoir were analysed, and we can draw some significant conclusions which can be adapted to improve the fracturing response in glutenite formation.

\section{Experimental Setup and Procedure}

2.1. Experimental Setup. The experiments are performed in a large-scale triaxial simulation test system. The system is composed of a triaxial assembly, a servo-booster pump, an acoustic emission instrument, a data acquisition system, 


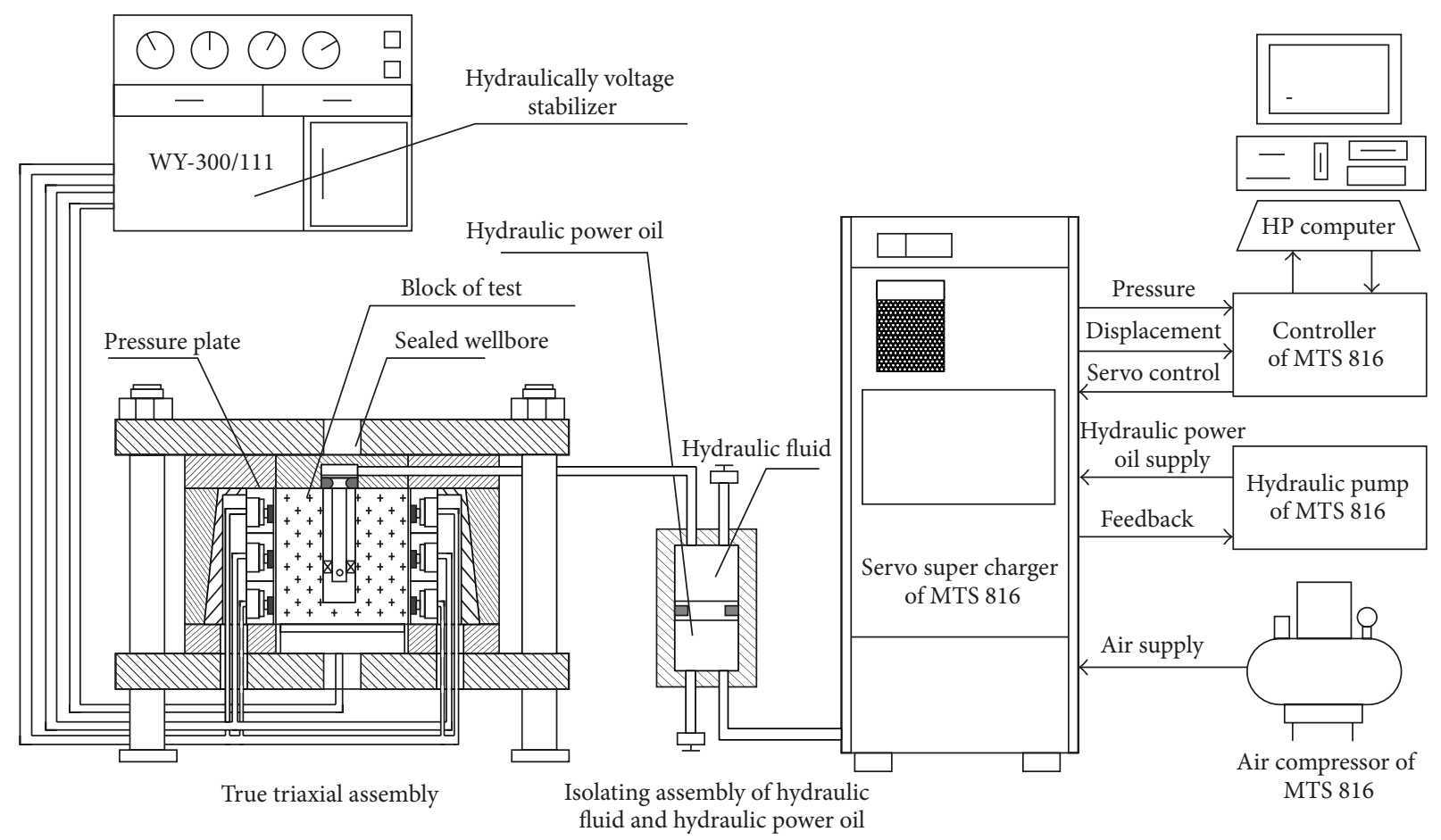

FIGURE 1: Schematic of a triaxial hydraulic fracturing test system.

a laboratory stabilized power supply unit, an oil-water isolating device, and other auxiliary devices (Figure 1).

Cubic blocks of $300 \mathrm{~mm}$ on a side are positioned between the pressure plates. In order to simulate the horizontal minimum principal stress, we add pressure, respectively, to the fractured interval and the top and bottom interlayer by three pairs of pressure plates in one horizontal direction. In the other horizontal and vertical direction, we simulate the vertical stress and horizontal maximum principal stress by a pair of pressure plates, respectively. The multichannel hydraulically voltage stabilizer provides pressure plates hydraulic pressure, and the pressure of every channel could be controlled (each channel for the biggest liquid pressure can reach $27 \mathrm{MPa}$ ).

The pressure platens are equipped with four square sheets to ensure equal pressure distribution. We used $0.1 \mathrm{~mm}$ thick Teflon sheets greased with Vaseline to reduce friction between the sample and the loading platens. The fluid injection pressure is provided by a servo-hydraulic pump (MTS 816).

Natural blocks or artificial blocks could be used for hydraulic fracturing experiment. Considering the difficulty of obtaining natural rock and the condition of processing, this paper conducts hydraulic fracturing with artificial rock. The experiment blocks were prepared with a special mould (Figure 2). The $10 \mathrm{~cm}$ section around the open hole was using the mixture of Chinese cement number 425, quartz sand, and gravel, and the other parts of the glutenite samples were mixed with Chinese cement number 425 and quartz sand. The mass ratio of cement to quartz sand was $1: 1$.

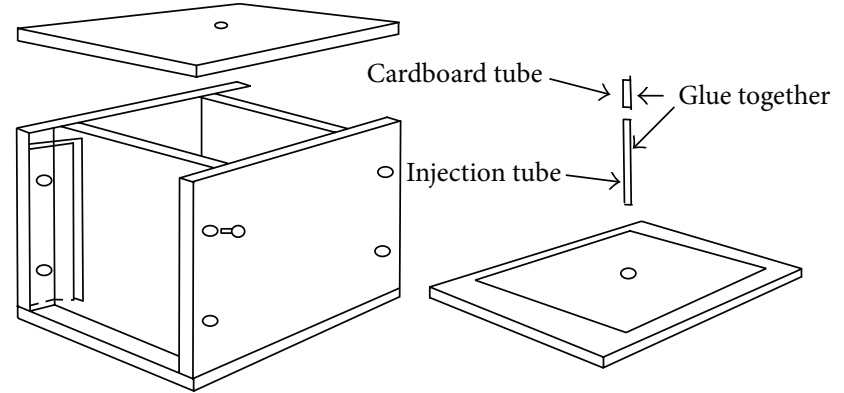

FIgURE 2: Artificial blocks moulds and bottom board assembly diagram.

2.2. Experiments Sample Preparation. A highly viscous $(135 \mathrm{mPa} \cdot \mathrm{s})$ guar gum fracturing fluid was used to initiate hydraulic fracture. We mixed a red dye in the fluid to improve detection of the hydraulic fracture.

The steps of preparing the glutenite samples are as follows. Firstly, cast a basement about $5 \mathrm{~cm}$ with cement and quartz sand at the bottom of the sample. Secondly, put a wellhole in the center of the sample. Then, the wellhole was perforated along $50 \mathrm{~mm}$ with $4 \mathrm{~mm}$ diameter perforations at 180-degree phasing, putting a fine screen mesh around the wellbore about a radius of $10 \mathrm{~cm}$ thin and casting with cement, quartz sand, and gravel inside the fine screen mesh (Figure 3). Thirdly, cast $15 \mathrm{~cm}$ high outside the fine screen mesh with cement and quartz. Finally, put out the fine screen mesh slowly, and cast the other parts of the sample with cement 


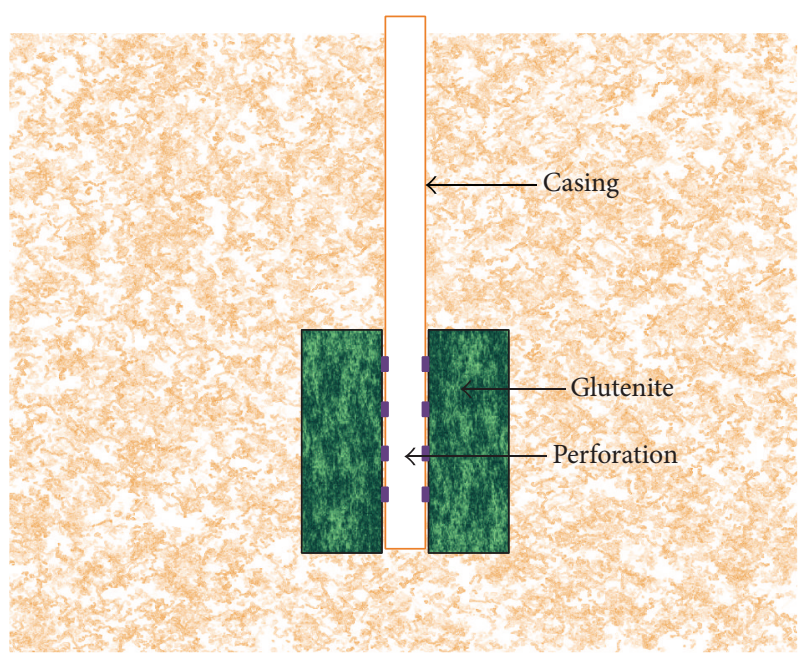

FIgURE 3: Artificial glutenite rock schemes.

and quartz. So the whole sample casting is completed. These model blocks were cured in a special mold for 5 days and then they were transferred outside for a fortnight at room temperature.

2.3. Test Procedure. We conducted our experiments in a normal-faulting stress regime. Guar gum fracturing fluid was used for the fracturing. The fluid was pumped into the bore hole with a constant rate until a fracture initiates and propagates after breakdown. The pressure decline was then recorded. After the experiment, each block was split open along the fracture plane to reveal the fracture geometry, which was subsequently photographed.

\section{Experimental Program}

In this paper, the primary purpose is to study the influence, caused by the gravel size, on the hydraulic fracture extension. So we prepare six artificial glutenite cores with different diameter range of gravel and prepare one sandstone core without gravel in contrast with the glutenite cores (Table 1). In our experiments, the value of the vertical compressive stress and the maximum horizontal principal stress is constant, and the value of the minimum horizontal principal stress is changed in some experiments, the purpose of which is to understand the minimum horizontal principal stress impact on the hydraulic fracture geometry and the fracture propagation pressure.

\section{Experimental Results and Analysis}

4.1. The Geometry of Hydraulic Fracture. In a series of experiments, the propagating direction of the hydraulic fracture in the glutenite reservoir is along the direction of maximum principal stress, which is consistent with the fracture in sandstone [5]. Yet there are large differences in fracture surface morphology. Figure 4 is the fracture cross-section of experimental sample along the maximum principal stress

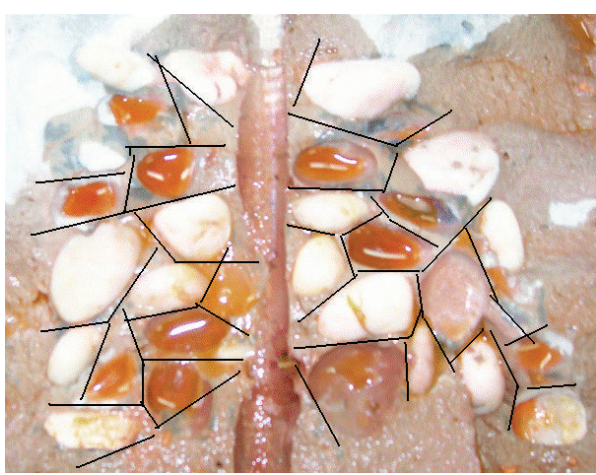

FIgURE 4: Fracture photo of sample number 1.

direction. This sample has the gravel diameter from 20 to 25 millimeters. The phenomenon of the gravels being splitted is not observed. The fractures propagate along the cement face of sandstone and glutenite, and the profile of fracture in glutenite formation looks like a spider's web. In the process of hydraulic fracture propagation, when the fracture encounters gravel, the direction of fracture propagation would be transformed, which causes roughness of the fracture surface. At the gravel, the width of the hydraulic fracture is narrower than elsewhere. The fracturing fluid mainly flows between the gravels and the channel that the fluid flow is narrow and bend, which is against the flow of the sand-carrying fluid. Characteristics of these fractures are significantly different from that in sandstone reservoir [8], in which the fissure surface is relatively smooth.

Therefore, in order to increase the liquidity of the carrier fluid and considering the complexity of the hydraulic fractures in glutenite formation, the hydraulic fracturing engineers should design lager rate to create a wider fracture and use multislug to smooth the hydraulic fracture.

4.2. The Characteristics of Extension Pressure. The distinct characteristic of hydraulic fracture propagation in glutenite formation is the sharp variation of extensions pressure. Figure 5 is the extending pressure curve of sample without gravel rock. The extension pressure is smooth, which is consistent with the experimental results as Yan et al. [6]. The pressure curve of these core samples with gravels is fluctuating, and the bigger the gravel diameter, the larger the variation of extensions pressure. Figure 6 is the pressure curve of sample with gravel diameter $16-22 \mathrm{~mm}$, in which the fracture extending pressure is very fluctuation.

The fracture pressure is mainly influenced by minimum principal stress, and the greater the minimum principal stress, the more the fracture pressure. Simultaneously, the value of gravel diameter influences the fracture pressure too. The bigger the gravel diameter, the greater the fracture pressure when the minimum principle pressures are equal. For example, the fracture pressure of number 5 core sample is greater than number 6 core sample (Table 2).

Table 2 describes crustal stress and net pressure of seven samples. The value of fracture propagation is influenced by the diameter of the gravel. The greater the diameter of gravel, 
TABLE 1: The parameters of hydraulic fracturing experiment.

\begin{tabular}{|c|c|c|c|c|c|c|c|}
\hline Number & $\begin{array}{l}\text { Loading speed } \\
\quad(\mathrm{mm} / \mathrm{sec})\end{array}$ & $\begin{array}{l}\text { Fluid viscosity } \\
\qquad(\mathrm{mPa} \cdot \mathrm{s})\end{array}$ & $\begin{array}{c}\text { Vertical } \\
\text { compressive } \\
\text { stress }(\mathrm{MPa})\end{array}$ & $\begin{array}{c}\text { Maximum } \\
\text { horizontal } \\
\text { principal stress } \\
(\mathrm{MPa})\end{array}$ & $\begin{array}{c}\text { Minimum } \\
\text { horizontal } \\
\text { principal stress } \\
(\mathrm{MPa})\end{array}$ & $\begin{array}{l}\text { Principal stress } \\
\text { difference } \\
(\mathrm{MPa})\end{array}$ & $\begin{array}{l}\text { Particle size } \\
\text { range }(\mathrm{mm})\end{array}$ \\
\hline 1 & 0.1 & 135 & 15 & 12 & 9 & 3 & $20-25$ \\
\hline 2 & 0.1 & 135 & 15 & 12 & 7 & 5 & $16-22$ \\
\hline 3 & 0.1 & 135 & 15 & 12 & 7 & 5 & Nongravel \\
\hline 4 & 0.1 & 135 & 15 & 12 & 5 & 7 & $12-18$ \\
\hline 5 & 0.1 & 135 & 15 & 12 & 5 & 7 & $10-15$ \\
\hline 6 & 0.1 & 135 & 15 & 12 & 3 & 9 & $8-12$ \\
\hline 7 & 0.1 & 135 & 15 & 12 & 3 & 9 & $6-10$ \\
\hline
\end{tabular}

TABLE 2: The pressure characteristics of the hydraulic fracture propagation.

\begin{tabular}{|c|c|c|c|c|c|c|}
\hline Number & $\begin{array}{c}\sigma_{H} \\
(\mathrm{Mpa})\end{array}$ & $\begin{array}{c}\sigma_{h} \\
(\mathrm{Mpa})\end{array}$ & $\begin{array}{c}\text { Fracture } \\
\text { pressure } \\
(\mathrm{Mpa})\end{array}$ & $\begin{array}{c}\text { Extension } \\
\text { pressure } \\
(\mathrm{Mpa})\end{array}$ & $\begin{array}{l}\text { Net pressure } \\
(\mathrm{Mpa})\end{array}$ & $\begin{array}{c}\text { Particle size } \\
\text { range } \\
\mathrm{mm}\end{array}$ \\
\hline 1 & 12 & 9 & 14.24 & 11.9 & 2.9 & $20-25$ \\
\hline 2 & 12 & 7 & 13.52 & 9.8 & 2.8 & $16-22$ \\
\hline 3 & 12 & 7 & 12.27 & 8.7 & 1.7 & non-gravel \\
\hline 4 & 12 & 5 & 12.27 & 7.6 & 2.6 & 12-18 \\
\hline 5 & 12 & 5 & 9.27 & 7.4 & 2.4 & $10-15$ \\
\hline 6 & 12 & 3 & 7.30 & 5.2 & 2.2 & $8-12$ \\
\hline 7 & 12 & 3 & 6.01 & 4.9 & 1.9 & $6-10$ \\
\hline
\end{tabular}

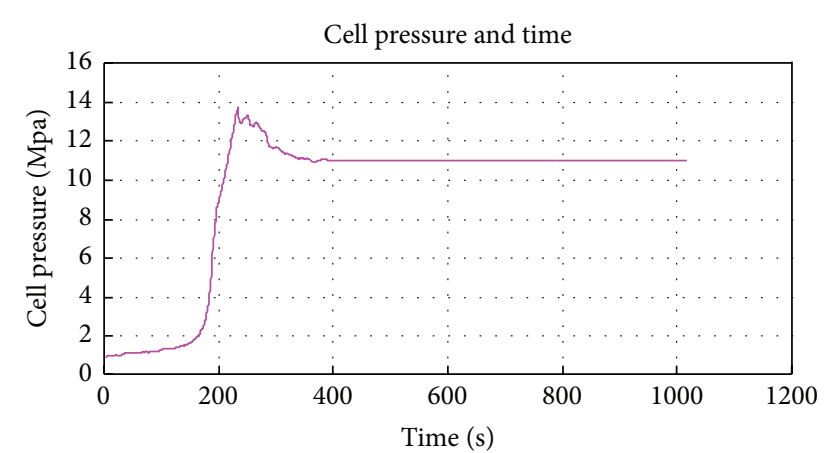

FIgURE 5: Pressure curve of sample number 2.

the larger the extension pressure. For example, the extension pressure of number 1 core sample, whose gravel diameter is 20-25 millimeter, is the greatest, and the extension pressure of number 6 core sample without gravel is the minimum (Table 2).

Consequently, it is necessary for hydraulic fracturing engineers to prepare for the extension pressure fluctuating when they design the fracturing treatment, and more proppant slugs should be adopted to smooth the fracture in glutenite formation, which would reduce the influence of the pressure fluctuating on fracturing and increase the exactness of the estimated fracturing operation by extension pressure.

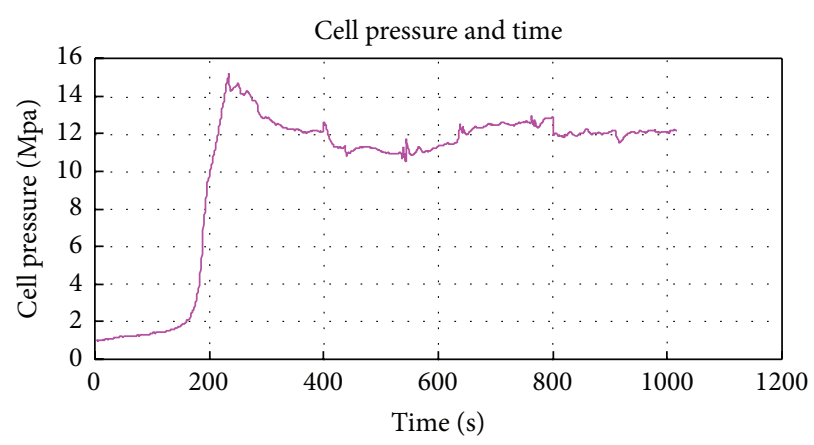

FIgURE 6: Pressure curve of sample number 3.

\section{Conclusions}

Based on the experimental study, the following major conclusions are made for fracturing in glutenite formation.

(1) Propagation of hydraulic fractures in glutenite formation has been analyzed by experiments. It is found that the fracture morphology in glutenite formation is more complex and rough, which is different from that of sandstone reservoir.

(2) Fractures in glutenite formation would propagate along the cement face instead of splitting the gravel. The face of fracture is relatively rough, which leads to the increase of flow resistance of fracturing fluid and higher injection pressure with heavy fluctuation. 
These characteristics have an important meaning to the fracturing design in glutenite formation.

(3) Large injection rate should be applied, based on the characteristic of fracture propagation. Wider fracture should be generated so that carrying fluid can pass easily. And the number of proppant slugs which is used to polish the faces of fracture should be increased to reduce injection pressure and pressure fluctuation.

(4) The risk of fracturing in glutenite formation can be reduced and thus success rate can be increased with the knowledge of fracture propagation characteristics in glutenite formation.

\section{Conflict of Interests}

The authors declare that there is no conflict of interests regarding the publication of this paper.

\section{Acknowledgments}

The paper is supported by Southwest Petroleum University (SWPU) Science and Technology Fund: Project name is hydraulic fracture and natural fracture interaction mechanism (no. 2013XJZ001). The authors would like to acknowledge the support of the Modeling of Fracture Network Conductivity in Shale Reservoir project (no. 51374178) which is sponsored by the National Natural Science Fund. This work was financially supported by the National Science and Technology Major Projects of China (no. 2008ZX05006).

\section{References}

[1] M. Chen, X. Z. Chen, and R. Z. Huang, "Hydraulic fracturing of highly deviated wells," Journal of University of Petroleum, vol. 19, no. 2, pp. 30-35, 1995 (Chinese).

[2] M. Chen, F. Pang, and Y. Jin, "Experiments and analysis on hydraulic fracturing by a large-size triaxial simulator," Chinese Journal of Rock Mechanics and Engineering, supplement 19, pp. 868-872, 2000 (Chinese).

[3] Y. Jin, X.-D. Zhang, and M. Chen, "Initiation pressure models for hydraulic fracturing of vertical wells in naturally fractured formation," Acta Petrolei Sinica, vol. 26, no. 6, pp. 113-118, 2005 (Chinese).

[4] B. Bohloli and C. J. de Pater, "Experimental study on hydraulic fracturing of soft rocks: influence of fluid rheology and confining stress," Journal of Petroleum Science and Engineering, vol. 53, no. 1-2, pp. 1-12, 2006.

[5] M. Chen, H. Jiang, G. Q. Zhang, and Y. Jin, “The experimental investigation of fracture propagation behavior and fracture geometry in hydraulic fracturing through oriented perforations," Petroleum Science and Technology, vol. 28, no. 13, pp. 1297-1306, 2010.

[6] T. Yan, W. Li, and X. Bi, "An experimental study of fracture initiation mechanisms during hydraulic fracturing," Petroleum Science, vol. 8, no. 1, pp. 87-92, 2011.

[7] Z. Liu, M. Chen, and G. Zhang, "Analysis of the influence of a natural fracture network on hydraulic fracture propagation in carbonate formations," Rock Mechanics and Rock Engineering, vol. 47, no. 2, pp. 575-587, 2014.
[8] B. Huang, P. Li, J. Ma, and S. Chen, "Experimental investigation on the basic law of hydraulic fracturing after water pressure control blasting," Rock Mechanics and Rock Engineering, vol. 47, no. 4, pp. 1321-1334, 2014. 

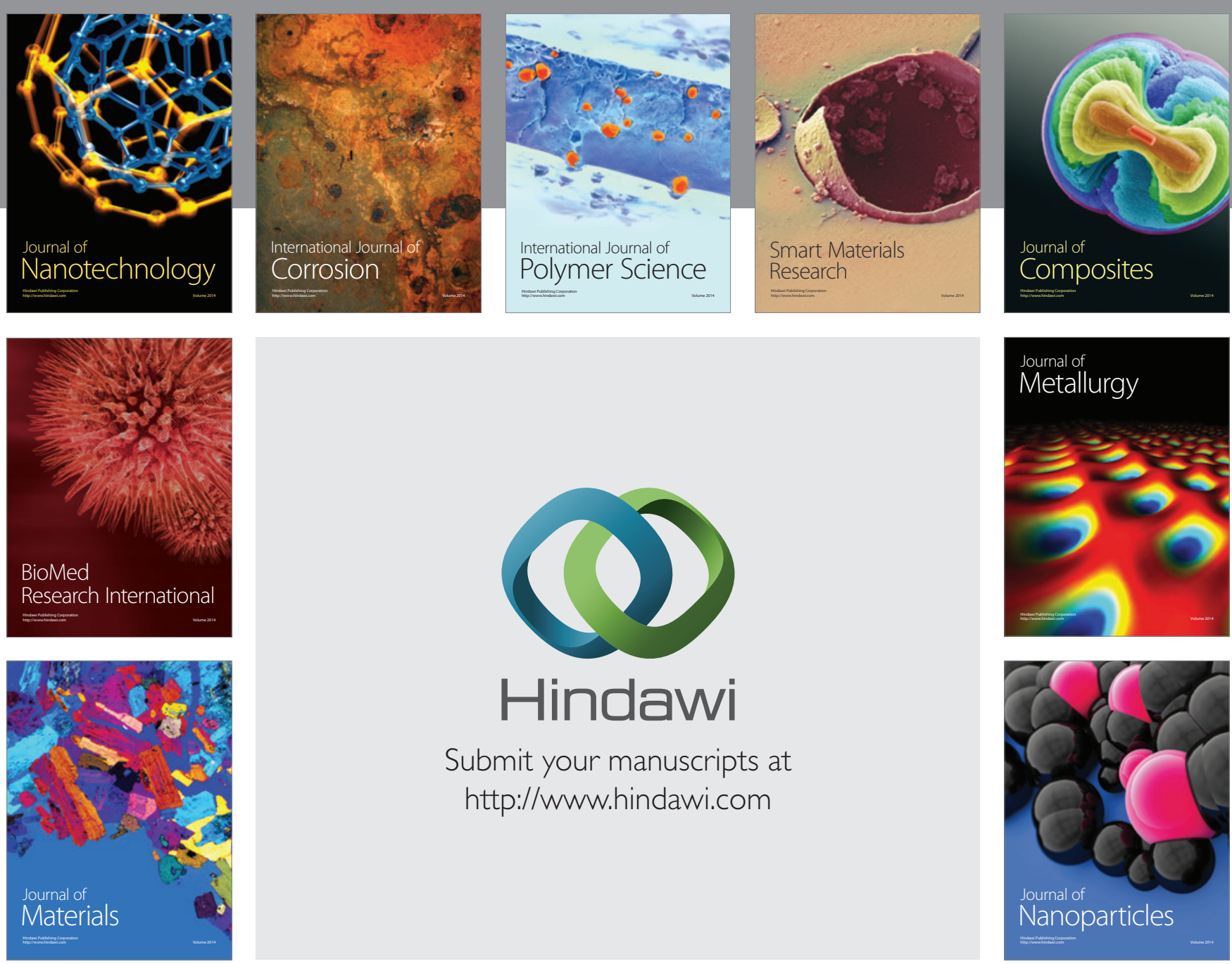

Submit your manuscripts at http://www.hindawi.com
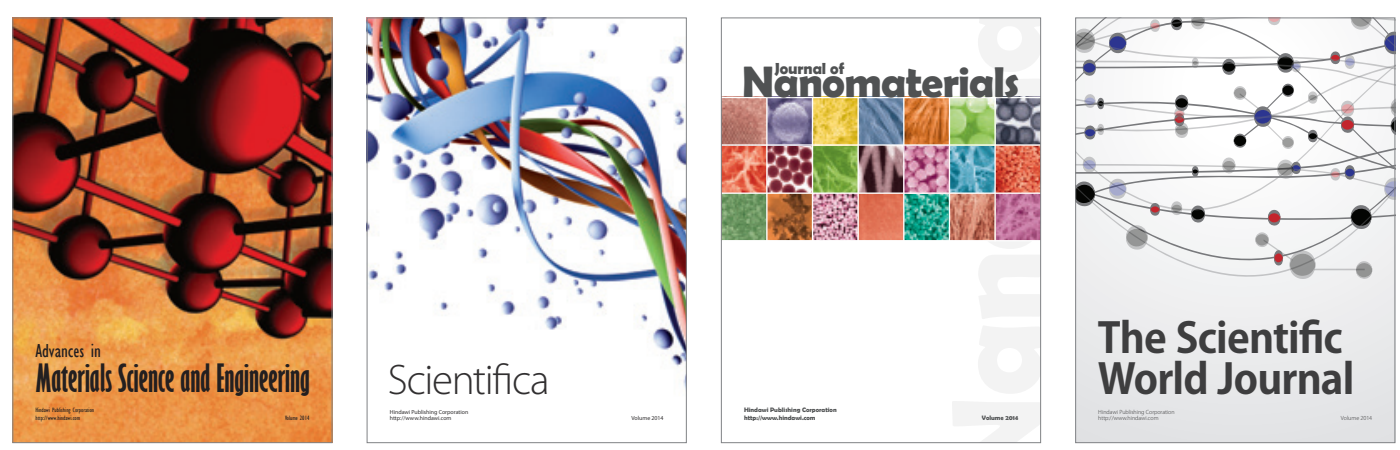

\section{The Scientific World Journal}
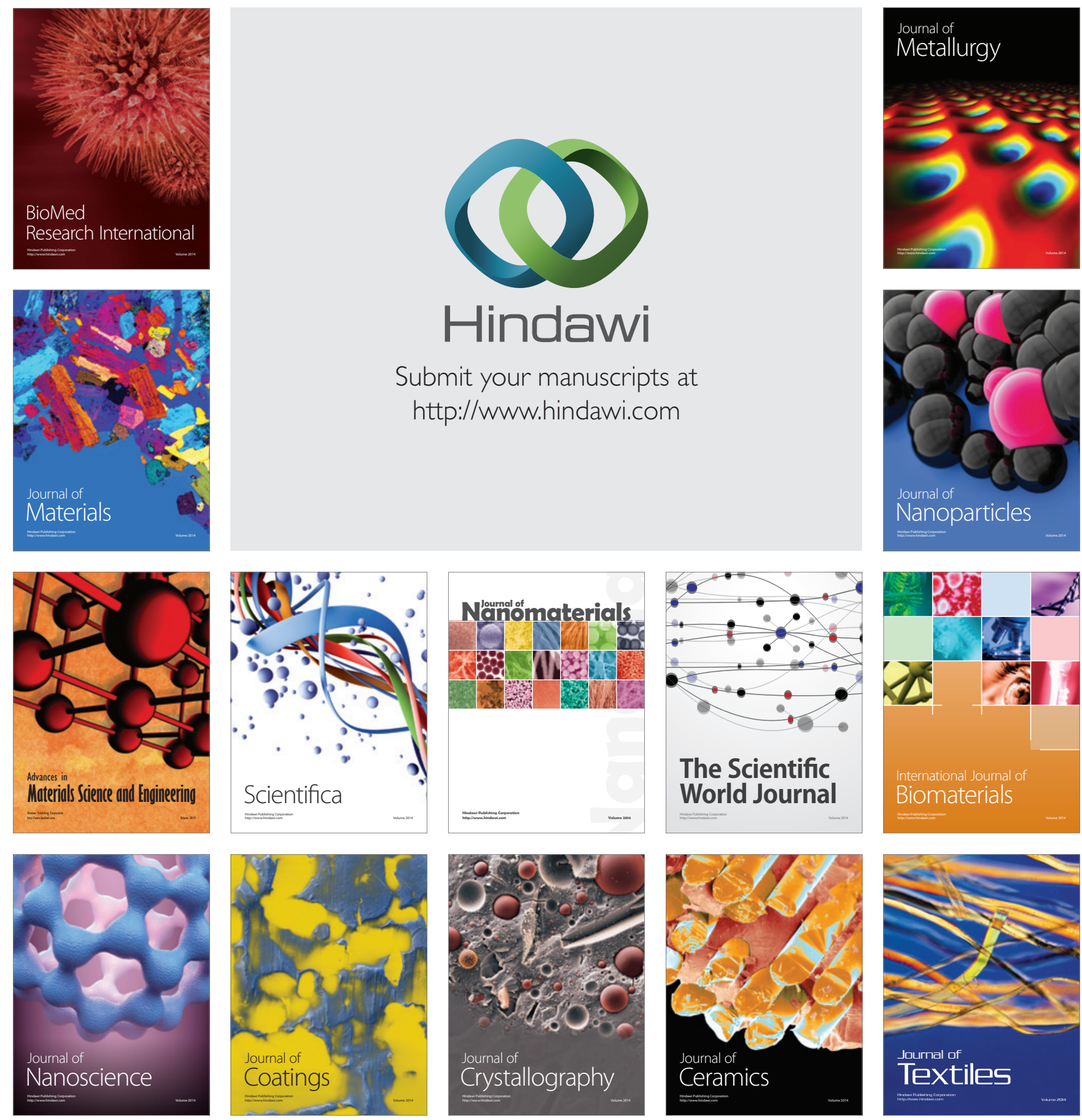